\title{
A comparison of risk of hypotension using standard doses of remifentanil versus dexmedetomidine infusions in adult patients undergoing surgery under general anaesthesia at the Aga Khan University Hospital, Nairobi
}

\author{
Maxine Onyango Okello ${ }^{1}$, Vitalis Mung'ayi ${ }^{1}$, Rodney Adam², Jimmie Kabugi ${ }^{1}$
}

1. Department of Anaesthesia, Aga Khan University, East Africa.

2. Department of Pathology, Aga Khan University, East Africa.

\section{Author details:}

Maxine Onyango Okello: Phone: + 25420366 2158, Email: maxine.okello@aku.edu; Vitalis Mung'ayi: Phone: +254 203662175 , Email: vitalis.mung'ayi@aku.edu; Rodney Adam: Phone: +254 20366 2238, Email: rodney.adam@aku.edu; Jimmie Kabugi: Phone: + 25420366 2158, Email: jimmie.kabugi@aku.edu

\section{Abstract}

Background: Remifentanil and dexmedetomidine are common agents used in general anaesthesia, monitored anaesthesia care and critical care. When combined with inhaled or intravenous anaesthetic agents intra-operatively, they provide analgesia, lower general anaesthetic requirements and provide sedation and analgesia in the peri-operative period if indicated. Pharmacodynamically, they cause hypotension and bradycardia which are reversible if well managed. Past studies of these drugs have shown a significant proportion of patients with hypotension when compared with similar agents or in isolation. This study compares these two drugs on the effect of hypotension when used as adjuncts to general anaesthesia at low dose standard rate of infusions.

Objective: To compare the proportion of hypotension episodes in a group of adult patients receiving dexmedetomidine infusion at $0.4 \mathrm{mcg} / \mathrm{kg} / \mathrm{hr}$ versus a group receiving remifentanil infusion at $0.2 \mathrm{mcg} / \mathrm{kg} / \mathrm{min}$, severity of hypotension and physician interventions in each group.

Methods: One hundred and four patients scheduled for elective surgery under general anaesthesia were randomized into two groups: Control group; received remifentanil infusion at $0.2 \mathrm{mcg} / \mathrm{kg} / \mathrm{min}$

Intervention group; received dexmedetomidine at $0.4 \mathrm{mcg} / \mathrm{kg} / \mathrm{hr}$.

General anaesthesia was standardized in both groups. The patients were blinded to the study. Baseline blood pressures of all patients were determined prior to induction. The patient's demographic characteristics were recorded. The number of patients who developed hypotension, the frequency of hypotension and the physician interventions were recorded and analysed.

Results: The age and gender characteristics were different between the two groups ( $\mathrm{p}$ values $<0.023$ and 0.05 respectively) however they did not affect the proportion of patients with hypotension. The weight, baseline pressures and ASA status of the patients within the groups were similar. The operative procedures varied within the groups. General surgery did not influence the outcome of hypotension in both arms. The duration of surgery in remifentanil group exceeded that of Dexmedetomidine $\mathrm{p}$ value $<0.0005$ however the time to the first episode of hypotension was similar between the groups. The episodes of hypotension were fewer in the dexmedetomidine arm and the proportion of patients with hypotension were higher in the remifentanil arm, p value $<0.001$, R.R $0 .=0.5938,95 \%$ C.I $=0.329-0.819$ The physician interventions administered were similar between the two groups except the use of ephedrine between the groups.

Conclusion: Among this population, at standard infusion rates, the proportion of patients that risk hypotension was greater in those undergoing elective surgery receiving remifentanil at $0.2 \mathrm{mcg} / \mathrm{kg} / \mathrm{min}$ than in dexmedetomidine at $0.4 \mathrm{mcg} / \mathrm{kg} / \mathrm{hr}$ under isoflurane based anaesthesia.

Keywords: Risk of hypotension, remifentanil versus dexmedetomidine infusions, general anaesthesia, Aga Khan University Hospital, Nairobi.

DOI: https://dx.doi.org/10.4314/ahs.v18i4.48

Cite as: Okello MO, Mung'ayi V, Adam R, Kabugi J. A comparison of risk of bypotension using standard doses of remifentanil versus dexmedetomidine infusions in adult patients undergoing surgery under general anaesthesia at the Aga Khan University Hospital, Nairobi. Afri Health Sci. 2018;18(4): 1267-

1282. bttps://dx.doi.org/10.4314/abs.v18i4.48

\section{Corresponding author:}

Vitalis Mung'ayi,

Department of Anaesthesia, Aga Khan University,

East Africa. Phone: +254 203662175

Email: mungayi@gmail.com

\section{Introduction}

Balanced anaesthesia is a triad of hypnosis/amnesia, analgesia and muscle relaxation. An ideal anaesthetic agent would be one drug that provides all three which is currently unavailable. With the exception of ketamine and

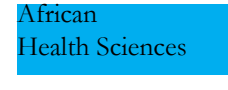

1267
(C) 2018 Okello et al. Licensee African Health Sciences. This is an Open Access article distributed under the terms of the Creative commons Attribution License (https://creativecommons.org/licenses/BY/4.0), which permits unrestricted use, distribution, and reproduction in any medium, provided the original work is properly cited. 
dexmedetomidine which have analgesic properties, inhaled volatile and intravenous anaesthetic agents have only amnestic/hypnotic properties ${ }^{1,2}$.

Balanced anaesthesia is provided by the use of hypnotic agents which could be intravenous or a volatile anaesthetic agent for example propofol and isoflurane, a muscle relaxant which may be used to provide intra-operative paralysis to skeletal muscle and analgesic agents to control pain and add the effect of sedation to the anaesthesia.

Short acting opioids such as remifentanil, fentanyl, alfentanil and sufentanil have been used intra-operatively as infusions for pain control and are combined with volatile inhalational agents or intravenous agents to provide general anaesthesia ${ }^{3}$. Remifentanil is the most common opioid used as an infusion intra-operatively at our hospital. It is associated with deep analgesia, has a fast recovery and deemed useful for patients who have a risk of intra-operative awareness, obstructive sleep apnoea and for patients who require early ambulation post-operatively ${ }^{4}$.

Remifentanil can be used as an adjunct with volatile anaesthetics and total intravenous anaesthesia with hypnotic agents ${ }^{5,6}$. At the appropriate doses, it can facilitate endotracheal intubation without muscle relaxant ${ }^{5}$. Remifentanil when used intra-operatively causes chest wall rigidity, hypotension and bradycardia, post-operatively with opioid induced tolerance or hyperalgesia, pruritus, nausea and vomiting which prolong recovery from general anaesthesia and surgery ${ }^{4,5}$.

Dexmedetomidine is a classical anaesthetic agent that has been gaining popularity since the early 1990's. It is an alpha 2 selective agonist which provides sedation and analgesia.

Dexmedetomidine is also used in general anaesthesia in various surgeries including major specialties such as cardiothoracic surgery and neurosurgery ${ }^{7}$. Dexmedetomidine has been used as analgesia post-operatively as an infusion for major cardiothoracic surgeries ${ }^{8,9}$. It has been shown to reduce intra-operative analgesic consumption and post-operative induced opioid hyperalgesia by acting centrally in the brain and spinal cord ${ }^{9,10,11,12,13,14}$.
Intra-operatively, dexmedetomidine reduces the MAC of inhaled anaesthetic agents as demonstrated by Wong et al and has been used in combination with propofol as total intravenous anaesthesia and patients did not portray any overt signs of intra-operative awareness ${ }^{10,15,16}$.

Dexmedetomidine and remifentanil are two different drugs that have a common effect of analgesia, sedation, hypotension and bradycardia. Bradycardia is treated with an anti-cholinergic agent. Hypotension is reduced/ treated by fluid boluses, titration/ discontinuation of the infusions and administration of vasopressors ${ }^{17,18}$.

It is established that remifentanil and dexmedetomidine cause hypotension at increasing therapeutic dose ranges. Standard doses which cause adequate anaesthesia/analgesia used are however lower than therapeutic doses and no studies have compared the proportion of patients with hypotension between patients receiving the two drugs under standard isoflurane anaesthesia in oxygen/air mixture at those rates of infusion.

Hypotension is a common side effect encountered during sedative/analgesic infusions administered as adjuncts of inhaled volatile and intravenous agents. Remifentanil infusions have been associated with high incidences of hypotensive episodes when compared to other opioids such as fentany ${ }^{21}$. Dexmedetomidine has been shown to have a lower incidence of hypotension when used peri-operatively $^{22}$.

Our study question was does the use of isoflurane anaesthesia plus dexmedetomidine infusion in adults undergoing elective surgery result in fewer cases of hypotension compared to isoflurane anaesthesia with remifentanil infusion? We hypothesized that at maintenance doses of $0.4 \mathrm{mcg} / \mathrm{kg} / \mathrm{hr}$ of dexmedetomidine and $0.2 \mathrm{mcg} / \mathrm{kg} /$ min of Remifentanil infusion there is no significant difference in the proportions of patients with hypotension between the two groups.

Our primary objective was to compare the proportion of hypotension cases developing following isoflurane anaesthesia plus dexmedetomidine infusion to isoflurane anaesthesia plus remifentanil at standard doses in adult patients undergoing elective surgery. Our secondary objectives were to compare the severity of the lowest mean 
arterial pressure recorded in hypotension among adult patients receiving dexmedetomidine infusion compared to those receiving remifentanil infusion, and to compare the number of physician interventions in each group.

\section{Methodology}

The study was performed following approval from the ethical and scientific review Committee at the Aga Khan University, East Africa. The study was registered by the Pan African Clinical Trials Registry registration number PACTR201412000962379. It was a single blinded randomized control trial. The target population included all adults aged between 18 and 85 years who underwent elective surgery at Aga Khan University Hospital, Nairobi. The sample population included 96 ASA I and II patients going to theatre for elective surgery between August 2014 and March 2015. Reasons for exclusion from the study were:

\section{Pregnancy}

2. Patients with severe liver and renal dysfunction

3. Patients diagnosed to have mental disorders

4. Pre-existing bradycardia and brady-dysrhythmia

5. Cardiovascular insufficiency and valvular heart disease

6. Hypotensive patients clinically diagnosed

7. Patients who declined to participate in the research

A sample size of 96 patients (48 per group) was calculated to be sufficient to demonstrate $27 \%$ difference in the proportion of hypotension between the remifentanil and dexmedetomidine group at a 95\% confidence level and a power of $80 \%$. A retrospective study looking at the haemodynamic impact of dexmedetomidine administration in 15,656 non-cardiac surgical cases showed a proportion of $26.5 \%$ in hypotension and a meta-analysis of 20 studies demonstrated it at $26 \% 0^{19,20}$. Sneyd et al demonstrated a proportion in hypotension of $53 \%$ in patients undergoing major abdominal and gynecological surgery using remifentanil infusion at $0.2 \mathrm{mcg} / \mathrm{kg} / \mathrm{min}^{21}$.

We therefore hypothesized that there would be no significant difference in the proportion of hypotension between the remifentanil group of patients receiving a standard dose rate of $0.2 \mathrm{mcg} / \mathrm{kg} / \mathrm{min}$ and the dexmedetomidine group receiving a standard dose rate of $0.4 \mathrm{mcg} / \mathrm{kg} / \mathrm{hr}$. The study participants were recruited from the pre-operative anaesthesia clinic (during the pre-anaesthetic review) and the in-patient surgical ward. All participants received verbal and written explanation on the purpose and procedure of the study from the principal investigator; and written informed consent. The patients who gave written informed consent were enrolled into the study and randomized. Their anaesthesia charts had indication of study patient for ease of identification on arrival in theatres. Simple randomization was done using a computer program which generated a random sequence of numbers. Each of the random numbers was sequentially assigned to either: Group D1; that would be on remifentanil infusion intra-operatively or Group D2; that would be on dexmedetomidine infusion intra-operatively

The patient was blinded to the study. The primary anaesthesia team and the principal investigator were not blinded due to near risk of adverse event of severe hypotension and bradycardia intra-operatively and the different preparation and administration of remifentanil and dexmedetomidine infusions. Dexmedetomidine was recently introduced into the Kenyan market and the anaesthesia team had limited experience with the drug. We sourced this drug for our study from our hospital pharmacy where it had been recently added to the hospital formulary. The recruitment process and patient distribution is illustrated in figure 1. 


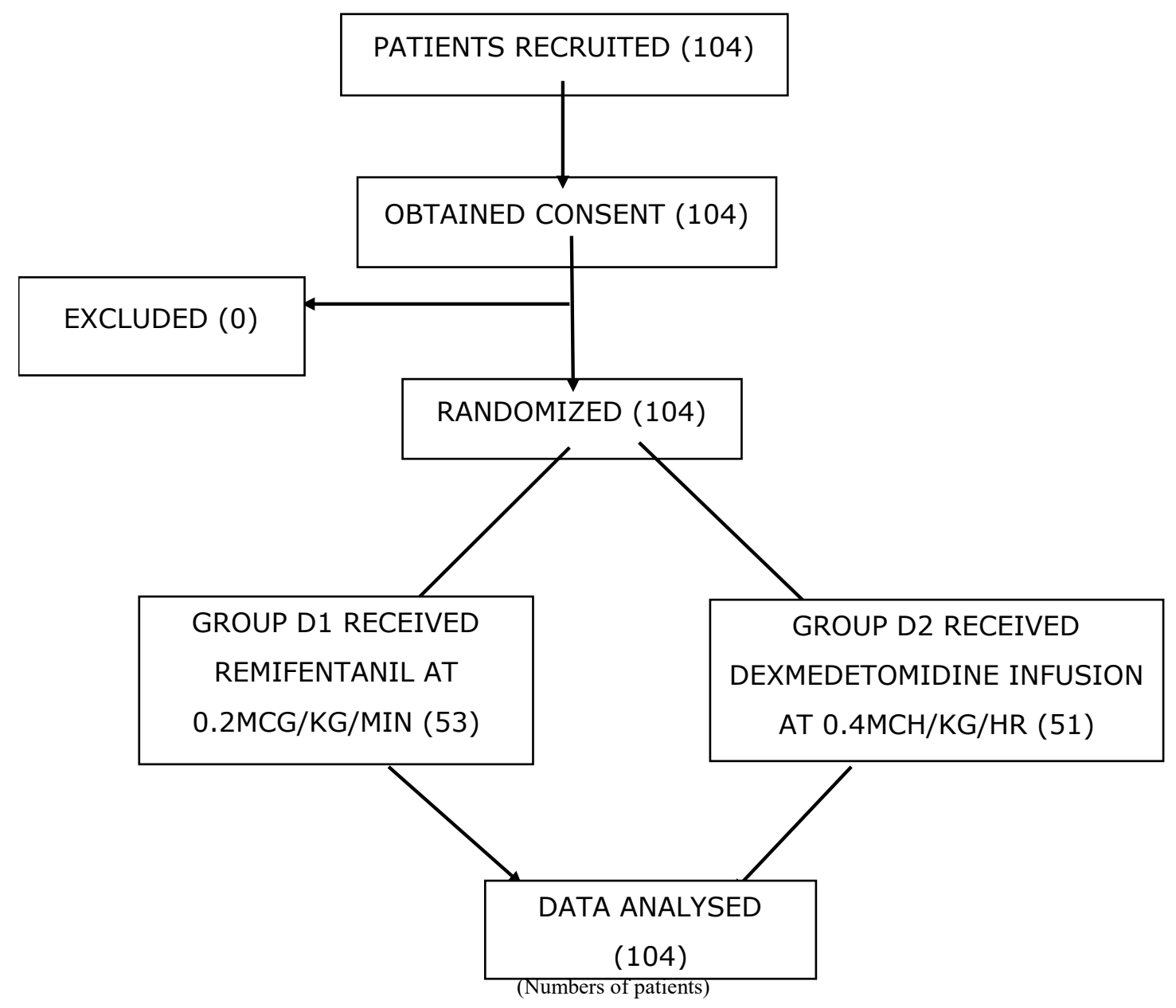

Figure 1: Flow diagram of patient distribution

This study was undertaken at the Aga Khan University Hospital, Nairobi operating theaters.

ASA I or II patients scheduled for elective surgical procedures were received in the pre-operative area. They had been randomized to receive remifentanil $0.2 \mathrm{mcg} / \mathrm{kg} /$ minute or dexmedetomidine at $0.4 \mathrm{mcg} / \mathrm{kg} / \mathrm{hour}$ after induction as an adjunct to isoflurane maintenance anaesthesia. The anaesthesia team conducting the anaesthesia received the anaesthetic chart with the attached data collection tool. The team included the consultant anaesthetist and the resident. The study drug was prepared by the anaesthesia residents who were not involved in the randomization process.

Remifentanil Ultiva ${ }^{\circledR} 2 \mathrm{mg}$ was diluted to $40 \mathrm{mls}$ with water for injection to constitute $50 \mathrm{mcg} / \mathrm{ml}$ and attached to an infusion pump. Dexmedetomidine Dexem ${ }^{\circledR}$ was diluted to $50 \mathrm{mls}$ with water for injection to constitute $4 \mathrm{mcg} /$ $\mathrm{ml}$ and attached to an infusion pump.

The infusion pumps used for the study were Injectomat TIVA Agilia anaesthesia syringe pump by Fresenius $\mathrm{Kabi}{ }^{\circledR}$. Once received into the operating rooms, the patient had standard monitoring equipment attached. These were temperature, non-invasive blood pressure, electrocardiography and pulse oximetry. The baseline cardiovascular and respiratory parameters were established- blood pressure, heart rate, respiratory rate and oxygen saturation. The baseline average mean arterial pressure was determined using mean arterial pressures on anaesthesia review, prior to entry into theater (in the wards) and prior to induction. 
Intravenous cannulation was achieved with standard B. Braun Venflow ${ }^{\circledR}$ cannula of Gauge 18. Hartmann's solution was run fully at $15 \mathrm{mls} / \mathrm{kg}$ as induction was initiated. No premedication was administered. The patient was then pre-oxygenated for three minutes. The patients randomized to D1 received remifentanil at a loading dose of $1 \mathrm{mcg} / \mathrm{kg}$ for 60 seconds and received propofol at 1.5 $\mathrm{mg} / \mathrm{kg}$ thereafter.

The patients randomized to D2 received dexmedetomidine at a loading dose of $1 \mathrm{mcg} / \mathrm{kg}$ for 10 minutes with propofol administered in the $7^{\text {th }}$ minute at $1.5 \mathrm{mg} / \mathrm{kg}$. Isoflurane was initiated after induction. Patients in both groups received Cisatracurium Nimbex ${ }^{\circledR}$ at $0.15-0.2 \mathrm{mg} /$ $\mathrm{kg}$ to facilitate endotracheal intubation and muscle paralysis.

Maintenance of Isoflurane was targeted at end tidals of $0.8-1.2 \%$ in an oxygen and air mixture at low flow anaesthesia. The infusion rates were targeted at the minimum dose rates in both groups $(0.05 \mathrm{mcg} / \mathrm{kg} / \mathrm{min}$ in remifentanil and $0.2 \mathrm{mcg} / \mathrm{kg} / \mathrm{hr}$ in dexmedetomidine) after induction prior to the first surgical stimulation. This was to avoid unnecessary episodes of hypotension prior to surgery.

Group D1 receiving remifentanil infusion had the maintenance rate initiated at $0.2 \mathrm{mcg} / \mathrm{kg} /$ minute and $0.4 \mathrm{mcg} /$ $\mathrm{kg} /$ hour for the patients in Group D2 receiving dexmedetomidine infusion at the start of surgical stimulation. Intra-operative intravenous fluid maintenance requirements were calculated using the Holiday- Segar regimen with Hartmann's solution. All patients received antiemetic medication of the anaesthetist choice and when indicated. Blood pressures were recorded as per standard protocol after induction every five minutes up to the end of anaesthesia.

Hypotension was defined as a 30\% reduction in the baseline mean arterial pressures. The hypotensive episodes occurring during surgery were noted and recorded on the data collection tool in each group. A fluid bolus of Hartmann's solution at $10 \mathrm{mls} / \mathrm{kg}$ was given to treat the first episode of hypotension. Subsequent episodes of hypotension were managed by administration of vasopressor boluses and fluid boluses at the anesthetist's discretion. The vasopressors used were either boluses of phenylephrine at $50 \mathrm{mcg} / \mathrm{ml}$ or ephedrine at $3 \mathrm{mg} / \mathrm{ml}$. When hypo- tension persisted for more than twenty minutes despite physician intervention, the dose was titrated downwards at decrements of 0.05 in remifentanil and 0.1 in the dexmedetomidine infusions. The infusion rate was recorded every 15 minutes.

When hypotension persisted despite vasopressor, fluid support and infusion titration to the minimum dose rate required, the infusions were discontinued and noted. Once mean arterial pressures returned to the baseline, the infusions were recommenced and titrated accordingly with the aim of resuming the standard rates of infusion or maintaining at rates well within the recommended prescriptions that did not yield hypotensive episodes and maintained anaesthesia/analgesia. In the event of hypertension i.e. MAPS that were a 30\% increase from the baseline, the rates of both infusions were increased gradually in increments of 0.1 for dexmedetomidine and 0.05 in remifentanil. The maximum therapeutic rate for dexmedetomidine was $0.7 \mathrm{mcg} / \mathrm{kg} / \mathrm{hr}$. and $0.5 \mathrm{mcg} / \mathrm{kg} / \mathrm{min}$ for remifentanil. Intraoperative bradycardia was treated with $300 \mathrm{mcg}$ of atropine intravenously.

Multimodal analgesia was administered as indicated. These included Paracetamol, non-steroidal anti-inflammatory drug (NSAID) when indicated intra-operatively and an opioid of the anesthetist's preferred choice intra-operatively as a sub-cutaneous injection half an hour to the end of the surgical procedure in the remifentanil group to avoid remifentanil-induced hyperalgesia post-operatively and upon reversal for the dexmedetomidine group to avoid increased sedation post-operatively. Dexmedetomidine was discontinued fifteen minutes before the end of surgery. Remifentanil, air and isoflurane were terminated five minutes to the end of surgery or on the last stitch. Reversal was conducted on appropriate oxygen flows. Atropine was given at $20 \mathrm{mcg} / \mathrm{kg}$, glycopyrrolate at $200 \mathrm{mcg}$ for each $1 \mathrm{mg}$ of neostigmine which was given at $50 \mathrm{mcg} /$ kg. Patients were reversed from anaesthesia and transferred to the post-anaesthesia care unit (PACU).

Intra-operative data was collected by the anaesthesia team using the data collection form.

At PACU, the form was verified by the principal investigator to ensure it was filled correctly post-operatively. The collected data material was placed in an envelope and stored in a lockable filing drawer in the supervisor's of- 
fice. All the sheets were checked once again to confirm completeness before being filed. The processed data was manually entered and saved in an external portable drive (USB) and copies were kept in the supervisor's office. The collected data were then manually entered by the principal investigator into an MS-Excel data base for analysis.

Data collected was analyzed using SPSS software version 20 by IBM. It was presented in the form of tables and graphs. Mean values with standard deviations were used to describe the patients age, weight and baseline pressures i.e. MAPS, systolic and diastolic pressures, lowest MAP throughout surgery and volume of Hartmann's fluid boluses. Unpaired Student T- test was used to compare means between the two groups. Gender, ASA status, operative procedures and variables such as the use of vasopressors, titrated rate of infusion cessation of infusion were represented as proportions and compared using the Pearson's chi square test or Fischer's exact test.

The proportion of hypotensive cases developing in isoflurane anaesthesia plus dexmedetomidine infusion and in remifentanil respectively were presented and compared using Fischer's exact test. The relative risk ratio was also calculated between the two groups and with confidence intervals. The tests were calculated under the assumption of equal variance. P-values $\leq 0.05$ were considered statistically significant. The collected data was kept private and confidential at all times.

\section{Results}

One hundred and four ASA I and II patients scheduled to undergo elective surgery were recruited to this study. There was no loss to follow-up of patients during recruitment and pre-operatively. The patient demographics and baseline characteristics are illustrated in table 1.

Student t-test was used to compare age and between the two groups, whereas Pearson's chi square test was used to compare the gender and ASA status. There was no statistical difference in the patient's weight and ASA status between the groups. However significant $\mathrm{p}$ values were generated from the age and gender. These statistical significances could influence the outcome of the study despite it being a result of chance from the process of randomization and clinically may be of value. 
Table 1: Patient characteristics

\begin{tabular}{|c|c|c|c|c|}
\hline & $\begin{array}{l}\text { Overall } \\
N=104\end{array}$ & $\begin{array}{l}\text { Remifentanil } \\
\text { Group } n=53\end{array}$ & $\begin{array}{l}\text { Dexmedetomidine } \\
\text { Group } n=51\end{array}$ & P-value \\
\hline Age in Years & $\begin{array}{l}36 \pm 12.00 \\
(18-75)\end{array}$ & $\begin{array}{l}36.37 \pm 10.34 \\
(18-70)\end{array}$ & $\begin{array}{l}41.72 \pm 13.00 \\
(19-75)\end{array}$ & 0.023 \\
\hline \multicolumn{5}{|l|}{ Sex } \\
\hline Male & $50(48.08 \%)$ & $31(58.48 \%)$ & $19(37.25 \%)$ & \multirow[t]{2}{*}{0.05} \\
\hline Female & $54(51.92 \%)$ & $22(41.52 \%)$ & $32(62.75 \%)$ & \\
\hline Weight in $\mathrm{KG}$ & $\begin{array}{l}75.16 \pm 17.59 \\
(41.5-154)\end{array}$ & $\begin{array}{l}72.38 \pm 11.32 \\
(52-103)\end{array}$ & $\begin{array}{l}78.04 \pm 22.07 \\
(41.5-154)\end{array}$ & 0.1188 \\
\hline \multicolumn{5}{|l|}{ ASA STATUS } \\
\hline I & $61(58.65 \%)$ & $32(57.4 \%)$ & $29(56.86 \%)$ & \multirow[t]{2}{*}{0.8692} \\
\hline II & $43(41.35 \%)$ & $21(42.6 \%)$ & $21(43.14 \%)$ & \\
\hline
\end{tabular}

ASA- American Society of Anaesthesiologists. NS- Not Statistically significant mean, standard deviation, minimum and maximum ranges in brackets are given for Age and weight. Proportions are demonstrated in the ASA status.

More than $50 \%$ of the elective procedures were from general surgery and orthopedics. Although the types of surgeries conducted was not analyzed, their nature could have influenced the proportion of hypotension between the groups. This is illustrated in table 2 . 
Table 2: Operative procedures

\begin{tabular}{|c|c|c|c|c|}
\hline & $\begin{array}{l}\text { Overall } \\
\mathrm{N}=104\end{array}$ & $\begin{array}{l}\text { Remifentanil } \\
\text { Group } n=53\end{array}$ & $\begin{array}{l}\text { Dexmedetomidine } \\
\text { Group } \mathbf{n}^{1}=51\end{array}$ & P value \\
\hline $\begin{array}{l}\text { General } \\
\text { Surgery }\end{array}$ & $34(32.69 \%)$ & $10(18.9 \%)$ & $24(47.1 \%)$ & \multirow[t]{8}{*}{0.084} \\
\hline Gynaecology & $24(23.08 \%)$ & $16(30.2 \%)$ & $8(15.7 \%)$ & \\
\hline $\begin{array}{l}\text { Maxillofacial } \\
\text { surgery }\end{array}$ & $6(5.77 \%)$ & $3(5.7 \%)$ & $3(5.9 \%$ & \\
\hline Neurosurgery & $5(4.81 \%)$ & $3(5.7 \%)$ & $2(3.9 \%)$ & \\
\hline $\begin{array}{l}\text { Orthopedic } \\
\text { surgery }\end{array}$ & $26(25.00 \%)$ & $14(26.4 \%)$ & $12(23.5 \%)$ & \\
\hline $\begin{array}{l}\text { Plastic } \\
\text { Surgery }\end{array}$ & $2(1.92 \%)$ & $2(3.8 \%)$ & $0(0.0 \%)$ & \\
\hline $\begin{array}{l}\text { Ear Nose } \\
\text { and } \\
\text { Throat } \\
\text { Surgery }\end{array}$ & $5(4.81 \%)$ & $4(7.5 \%)$ & $1(2 \%)$ & \\
\hline $\begin{array}{l}\text { Urology } \\
\text { surgery }\end{array}$ & $2(1.92 \%)$ & $1(1.89 \%)$ & $1(1.96 \%)$ & \\
\hline
\end{tabular}

Fisher's exact test was used to compare the distribution of surgical procedures between he two groups.

The duration of surgery was greater in the patients receiving remifentanil infusion compared those receiving dexmedetomidine infusion and was statistically significant as illustrated in table 3. This was a result of the recruitment process. The baseline pressures prior to commencing surgery between the two groups were similar. 
Table 3: Duration of surgery

\begin{tabular}{|c|c|c|c|c|}
\hline & $\begin{array}{l}\text { Overall } \\
N=104\end{array}$ & $\begin{array}{l}\text { Remifentanil il Group } \\
\mathrm{n}=53\end{array}$ & $\begin{array}{l}\text { Dexmedetomidine } \\
\text { Group } n^{1}=51\end{array}$ & P value \\
\hline $\begin{array}{l}\text { Duration of } \\
\text { Surgery in } \\
\text { minutes }\end{array}$ & $101.54 \pm 51.35$ & $\begin{array}{l}121.75 \pm 54 . \\
45\end{array}$ & $80.54 \pm 38.27$ & $<0.0005$ \\
\hline $\begin{array}{l}\text { BASELINE } \\
\text { MAPS } \\
(\mathrm{mmHg})\end{array}$ & $\begin{array}{l}88.89 \pm 12.94 \\
(60-120)\end{array}$ & $\begin{array}{l}72.38 \pm 11.3 \\
3(65-120)\end{array}$ & $\begin{array}{l}78.04 \pm 22.08 \\
(60-114)\end{array}$ & 0.1011 \\
\hline $\begin{array}{l}\text { BASELINE } \\
\text { SYSTOLIC } \\
\text { PRESSURE } \\
(\mathrm{mmHg})\end{array}$ & $\begin{array}{l}119.40 \pm 15.78 \\
(100-145)\end{array}$ & $\begin{array}{l}119.00 \pm 11 \\
64(100- \\
144)\end{array}$ & $\begin{array}{l}121.68 \pm 11.53 \\
(100-145)\end{array}$ & 0.2279 \\
\hline $\begin{array}{l}\text { BASELINE } \\
\text { DIASTOLIC } \\
\text { PRESSURES } \\
(\mathrm{mmHg})\end{array}$ & $\begin{array}{l}74.13 \pm 10.10 \\
(50-101)\end{array}$ & $\begin{array}{l}73.77 \pm 11.1 \\
0(50-101)\end{array}$ & $74.51 \pm 9.04(54-95)$ & 0.7107 \\
\hline
\end{tabular}

$\mathrm{MmHg}$ - millimeters of Mercury, minimum and maximum values are in brackets.

The means of the pressures between the two groups was compared with unpaired t-test.

The use of NSAIDs when compared between the two groups did not yield any statistical significance. Paracetamol was used in all recruited patients. Morphine was the most common opioid analgesic preferred by the an- aesthesia team. There was greater administration of morphine in patient's receiving remifentanil. This was based on the preference of the anaesthesia team and was statistically significant. This is illustrated in table 4. 
Table 4: Analgesia administered in the operating room

\begin{tabular}{|c|c|c|c|c|}
\hline \multicolumn{5}{|c|}{ ANALGESIA } \\
\hline & $\begin{array}{l}\text { Overall } \\
\mathrm{N}=104\end{array}$ & $\begin{array}{l}\text { Remifentanil } \\
\text { Group } n=53\end{array}$ & $\begin{array}{l}\text { Dexmedetomidine } \\
\text { Group } \mathbf{n}^{1}=51\end{array}$ & $P$ value \\
\hline Paracetamol & $104(100 \%)$ & $53(100 \%)$ & $51(100 \%)$ & 1 \\
\hline NSAIDs & $89(85.58 \%)$ & $44(83 \%)$ & $45(88.2 \%)$ & 0.449 \\
\hline $\begin{array}{l}\text { NSAIDs } \\
\text { Avoided }\end{array}$ & $15(14.42 \%)$ & $9(17 \%)$ & $6(9.8 \%)$ & \\
\hline \multicolumn{5}{|c|}{ OPIOID USE } \\
\hline Morphine & $90(86.54 \%)$ & $51(96.22 \%)$ & $39(76.47 \%)$ & 0.2365 \\
\hline Pethidine & $3(2.88 \%)$ & $1(1.89 \%)$ & $2(3.92 \%)$ & \\
\hline Tramadol & $4(3.85 \%)$ & $0(0.00 \%)$ & $4(7.84 \%)$ & \\
\hline None & $7(6.73 \%)$ & $1(1.89 \%)$ & $6(11.6 \%)$ & \\
\hline
\end{tabular}

Pearson's uncorrected Chi square test was used to compare the use of analgesia between the two groups.

The proportion of hypotension episodes developing between patients receiving dexmedetomidine infusion and remifentanil infusion is illustrated in the figure 2 and table 5. 
Figure 2 showing the proportion of patients who developed hypotension between the two groups.

\section{PATIENTS WITH HYPOTENSION}

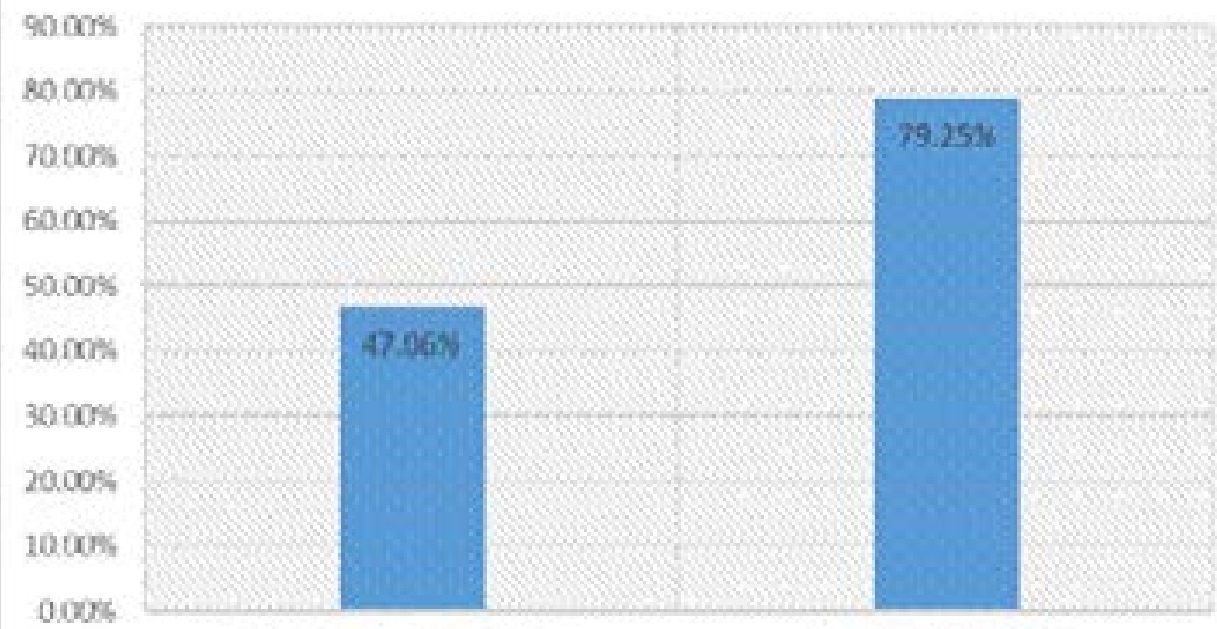

Deveredetomidine infosion

Rentiferataril infusion

$\mathrm{P}$ value using Fischer's exact test $<0.001$

Table 5: Relative risk ratio for having at least one hypotensive episode

\begin{tabular}{|l|l|l|l|}
\hline & Hypotension & $\begin{array}{l}\text { Normal } \\
\text { Blood } \\
\text { Pressure }\end{array}$ & TOTAL \\
\hline $\begin{array}{l}\text { Dexmedetomidine } \\
\text { infusion }\end{array}$ & $24(47.06 \%)$ & $27(52.94 \%)$ & 51 \\
\hline Remifentanil infusion & $42(79.25 \%)$ & $11(20.75 \%)$ & 53 \\
\hline R.R= 0.5938 & & & \\
\hline 95\% \\
C.I= 0.329-0.819
\end{tabular}

R.R- Relative Risk ratio, C.I-Confidence interval 
There was a greater proportion of hypotension in patient's receiving remifentanil versus patients receiving dexmedetomidine $(79.25 \%$ against $47.06 \%)$ at standard rates of $0.2 \mathrm{mcg} / \mathrm{kg} /$ minute versus $0.4 \mathrm{mcg} / \mathrm{kg} / \mathrm{hour}$. The proportion of patients with a hypotensive episode between each group was statistically significant ( $p$ val- ue $<0.0001)$. The risk ratio being less than 1 implied the likelihood of hypotension developing in patients receiving remifentanil infusion at $0.2 \mathrm{mcg} / \mathrm{kg} / \mathrm{minute}$ was $59.38 \%$.

There were more episodes of hypotension in the remifentanil arm (3.04 per patient) than in the Dexmedetomidine $\operatorname{arm}(2.08$ per patient) as illustrated in table 6 .

Table 6: Number of hypotensive episodes in patients with hypotension during surgery

\begin{tabular}{|c|c|}
\hline & $\begin{array}{r}\text { EPISODES OF } \\
\text { HYPOTENSION }\end{array}$ \\
\hline Remifentanil $\mathbf{n}=\mathbf{4 2}$ & 128 \\
\hline Dexmedetomidine $\mathbf{n}^{\mathbf{1}}=\mathbf{2 4}$ & 50 \\
\hline
\end{tabular}

Comparison of the lowest hypotensive MAP was done The lowest hypotensive mean arterial pressures between using independent student $t$ test. the two groups recorded were similar and not statistically significant as shown in table 7. This is clinically satisfactory.

Table 7: The lowest hypotensive MAP recorded during surgery

\begin{tabular}{|l|l|l|l|l|}
\hline & $\begin{array}{l}\text { Overall } \\
\text { N=66 }\end{array}$ & $\begin{array}{l}\text { Remifentanil } \\
\text { Group } \mathbf{n = 4 2}\end{array}$ & $\begin{array}{l}\text { Dexmedetomidine } \\
\text { Group } \mathbf{n}^{\mathbf{1}}=\mathbf{2 4}\end{array}$ & P-value \\
\hline $\begin{array}{l}\text { MAPs of the } \\
\text { lowest episode } \\
\text { of } \\
\text { hypotension in } \\
\text { mmHg }\end{array}$ & $53.81 \pm 7.48$ & $53.34 \pm 7.22$ & $54.63 \pm 7.98$ & 0.5040 \\
\hline
\end{tabular}

MmHg- Millimeters of mercury 
The management required variable physician interventions which included: -

1. Administration of Hartmann's solution boluses.

2. The administration of vasopressors.

3. Titration of infusions.

4. Termination of the infusions.
These were options left to the discretion of the team. They were used as single or combined treatments. Forty five patients from both arms received Hartmann's fluid bolus. $65.96 \%$ of the patients who experienced hypotension were in the remifentanil arm against $48.15 \%$ in the Dexmedetomidine arm. Volumes received in both arms of the study is illustrated in table 8 .

Table 8: Volume of Hartmann's fluid boluses administered to treat the patients with hypotension

\begin{tabular}{|l|l|l|l|l|}
\hline & Overall N=45 & $\begin{array}{l}\text { Remifentanil } \\
\text { Group n=31 }\end{array}$ & $\begin{array}{l}\text { Dexmedetomidine } \\
\text { Group } \mathbf{n}^{\mathbf{1}}=\mathbf{1 4}\end{array}$ & P value \\
\hline $\begin{array}{l}\text { Volume of } \\
\text { Hartmann's } \\
\text { boluses } \\
\text { given in mls }\end{array}$ & $\begin{array}{l}181.81 \pm 106.25 \\
(100-500)\end{array}$ & $\begin{array}{l}187.1 \pm 111.78 \\
(100-500)\end{array}$ & $\begin{array}{l}169.23 \pm 94.73 \\
(100-400)\end{array}$ & 0.6064 \\
\hline
\end{tabular}

The means of the volume of Hartmann's fluid bolus of the two groups were compared with unpaired t-test.

The mean volume infused in the dexmedetomidine groupwas less compared to the remifentanil arm but there was no statistical significance. $19.70 \%$ of the patients who developed hypotension received ephedrine and $28.78 \%$ received phenylephrine. The use of ephedrine between the groups was significant as illustrated in table 9. Fish- er's exact test was used to compare the two groups. The proportion of patients requiring the infusion rates to be titrated downwards was similar between the two groups at $79.17 \%$ in the dexmedetomidine group and $85.71 \%$ in the remifentanil group. The minimum rate of infusion in each group remained in the recommended dose ranges suitable for anaesthesia in patient's undergoing surgery. 
Table 9: Use of vasopressors in patients with hypotension during surgery

\begin{tabular}{|l|l|l|l|l|}
\hline & $\begin{array}{l}\text { Overall } \\
\text { N=66 }\end{array}$ & $\begin{array}{l}\text { Remifentanil 1 } \\
\text { Group n=42 }\end{array}$ & $\begin{array}{l}\text { Dexmedetomidine } \\
\text { Group } \mathbf{n}^{\mathbf{1}} \mathbf{2 4}\end{array}$ & P value \\
\hline Ephedrine & $13(19.7$ & $4(9.52 \%)$ & $9(37.5 \%)$ & 0.036062 \\
\hline & $\begin{array}{l}\text { Overall } \\
\mathbf{N}=\mathbf{6 6}\end{array}$ & $\begin{array}{l}\text { Remifentanil } \\
\text { Group } \mathbf{n}=\mathbf{4 2}\end{array}$ & $\begin{array}{l}\text { Dexmedetomidine } \\
\text { Group } \mathbf{n}^{\mathbf{1}}=\mathbf{2 4}\end{array}$ & P-value \\
\hline Phenylephrine & $19(28.78 \%)$ & $13(30.10 \%)$ & $6(25.00 \%)$ & 0.0 \\
\hline
\end{tabular}

The proportion of patients requiring termination of the infusion was higher in the remifentanil arm at $11.90 \%$ while the dexmedetomidine group had none. This was statistically insignificant following comparison of the two study arms with Fischer's exact test $p=0.1499$. The average rate of infusion of remifentanil and dexmedetomidine in the patients recruited in this study was $0.154 \mathrm{mcg} /$ $\mathrm{kg} / \mathrm{minute}(\mathrm{S} . \mathrm{D} \pm 0.05)$ and $0.39 \mathrm{mcg} / \mathrm{kg} / \mathrm{hour}(\mathrm{S} . \mathrm{D} \pm 0.13)$ respectively.

\section{Discussion}

Intra-operative hypotension remains a common side effect of inhaled and intravenous anaesthetics agents used in general anaesthesia. This study demonstrated that there was a significantly higher proportion of patients receiving remifentanil infusion who developed hypotension than those on dexmedetomidine. Among patients in either group who developed hypotension, the hypotensive episodes were also more frequent in the patients receiving remifentanil infusion.

Salman and his colleagues compared remifentanil to dexmedetomidine at similar infusion rates in females undergoing ambulatory laparoscopic gynecological procedures $^{23}$. The loading dose during induction was ten minutes in each group whereas in this study, remifentanil was loaded for one minute as prescribed.

Their baseline characteristics including duration of surgeries were similar between the two groups. The popula- tion in this study had both gender and heterogeneous operative procedures. They used BIS monitoring to ensure standardized depth of anaesthesia which was not used here. They noted the systolic blood pressures between the two groups were similar and did not report hypotension throughout surgery. The results in the current study have shown that hypotension does occur at these rates of infusion and is frequent 2.7 vs 2.1 per patient in remifentanil and dexmedetomidine respectively. The current study demonstrated that despite the occurrence of hypotension, the lowest mean arterial pressure readings during surgery between the two groups was clinically acceptable. No adverse cardiovascular events were reported requiring resuscitation which is similar to Salman's findings.

Jung et al compared the haemodynamic profile of remifentanil and dexmedetomidine infusions at varying infusion protocols and the blood pressures were significantly lower in patients on dexmedetomidine ${ }^{24}$. This is different from the current results. Although infusion rates were well within the recommended doses, their infusion rates were as high as $0.7 \mathrm{mcg} / \mathrm{kg} /$ hour, which is higher than the $0.4 \mathrm{mcg} / \mathrm{kg} /$ hour used in the current study. Thus, it is possible that the higher rates of hypotension were due to their higher infusion rates. The lowest mean arterial pressure during surgery was similar between the two groups revealing the safety profile of both drugs during surgery and there were no cardiac adverse events and significant blood loss reported. 
The females enrolled in the study were slightly greater than males and did not influence the outcome of proportion of patients with hypotension between the groups. This was a result of the recruitment process. The proportion of patients with hypotension between the sexes was not significant $(\mathrm{p}=0.8023)$. Women physiologically have an active parasympathetic system, higher estrogen levels and a lower center of gravity which would influence blood pressure as demonstrated by Cheng and his colleagues ${ }^{25}$ but Sachin Kheterpal et al demonstrated that gender was not a predictor of cardiac adverse events peri-operatively in patients undergoing elective surgery ${ }^{26}$.

The average infusion rate of dexmedetomidine was $0.39 \mathrm{mcg} / \mathrm{kg} /$ hour indicating better hemodynamic stability in the population selected for the study. The average infusion rate of $0.154 \mathrm{mcg} / \mathrm{kg} / \mathrm{min}$ in remifentanil showed this could be the rate of infusion that provides haemodynamic stability in our population as opposed to $0.2 \mathrm{mcg} /$ $\mathrm{kg} / \mathrm{min}$ in this study.

The volume of Hartmann's solution administered as boluses was similar between the two groups. There was a greater preference in using phenylephrine than ephedrine in both arms. Using weight based infusions and calculating the percentage increase from the mean arterial pressure could have been a better measure of the value of volume boluses and managing hypotension. Ephedrine was commonly used to raise blood mean arterial pressures in the dexmedetomidine arm $(37.5 \%$ vs $8.51 \%$; $p$ $=0.007)$. The mode of managing hypotension was at the discretion of the anaesthetist. Comparing a single agent for example phenylephrine at $100 \mathrm{mcg}$ and determining the time period before the next hypotensive episode may have demonstrated the value of the vasopressors in managing episode between the two arms.

No study has determined the equipotent doses of remifentanil and dexmedetomidine. It would be very valuable but costly as laboratory tests are necessary for each patient. This would then enable us to induct studies in the same setting to yield better and accurate results.

This study has demonstrated the average rate of infusions required in remifentanil and dexmedetomidine in the Kenyan population undergoing surgery. It has also raised awareness on dexmedetomidine as an adjuvant to inhaled anaesthetic agents and its use peri-operatively.
The use of dexmedetomidine intra-operatively as a substitute to remifentanil infusion would result in a lower proportion of patients getting hypotension and fewer episodes during surgery. Other studies have shown it also reduces the risk of apnoea, nausea, vomiting and opioid induced hyperalgesia during recovery. The effect of lower sedation scores may be suitable in patients requiring sedation post-operatively. Termination of its infusion is very important in patients requiring prompt ambulation for example day care surgery

\section{Limitations}

Limitations to the study include the use of simple randomized sampling. We did not use Bispectral index (BIS) monitoring to ensure standard depth of anaesthesia and eliminate the probability of the inhaled anaesthetic agent contributing to the hypotension in patients. BIS monitoring is available at our hospital but is very costly. It would be unethical to extend the cost to the patient and the budget allocated for the study was short of covering the cost. Lastly our study had single blinding and this could have been a potential source of bias.

\section{Conclusion}

The conclusion to this study is that at standard infusion rates, the proportion of patients and risk hypotension is greater in patients undergoing elective surgery receiving remifentanil at $0.2 \mathrm{mcg} / \mathrm{kg} / \mathrm{min}$ than in dexmedetomidine at $0.4 \mathrm{mcg} / \mathrm{kg} / \mathrm{hr}$. under isoflurane anaesthesia.

\section{Conflit of interest}

None.

\section{References}

1. Subramaniam K, Subramaniam B, Steinbrook R a. Ketamine as adjuvant analgesic to opioids: a quantitative and qualitative systematic review. Anesth Analg. 2004 Aug; 99(2):482-95

2. Gertler R, Brown HC, Mitchell DH, Silvius EN. Dexmedetomidine: a novel sedative-analgesic agent. Proc (Bayl Univ Med Cent) 2001 Jan; 14(1):13-21.

3. Egan TD. Anesthesia The clinical pharmacology of remifentanil: a brief review. J Anesth. 1998;(12):195-204. PubMed.

4. Komatsu R, Turan AM, Orhan-Sungur M, McGuire J, Radke OC, Apfel CC. Remifentanil for general anaesthesia: a systematic review. Anaesthesia [Internet]. 2007 Dec; 62(12):1266-80.

African Health Sciences Vol 18 Issue 4, December, 2018 
5. Scott LJ, Perry CM. A Review of its Use during the induction and maintenance of general anaesthesia. Drugs. 2005; 65(13):1793-823. PubMed.

6. Hogue CW, Bowdle TA, O'Leary C, Duncalf D, Miguel R, Pitts M, et al. A multicenter evaluation of total intravenous anesthesia with remifentanil and propofol for elective inpatient surgery. Anesth Analg. 1996 Aug;83(2):279-85

7. Arcangeli a, D'Alò C, Gaspari R. Dexmedetomidine use in general anaesthesia. Curr Drug Targets. 2009 Aug; 10(8):687-95.

8. Ramsay MA, Newman KB, Leeper B, Hamman BL, Hebeler RF, Henry AC, et al. Dexmedetomidine infusion for analgesia up to 48 hours after lung surgery performed by lateral thoracotomy. Proc (Bayl Univ Med Cent). 2014 Jan; 27(1):3-10.

9. Blaudszun G,Lysakowski C, Elia N, Tramer MR. Effect of perioperative systemic $\alpha 2$ agonists on postoperative morphine consumption and pain intensity:systematic review and meta-analysis of randomized controlled trials. Anesthesiology. 2012 Jun;116(6) :1312-22

10. Bulow NM, Barbosa NV, Rocha JB. Opioid consumption in total intravenous anesthesia is reduced with dexmedetomidine: a comparative study with remifentanil in gynecologic videolaparoscopic surgery. J Clin Anesth. 2007 Jun; 19(4):280-5.

11. Angst MS, Clark JD. Opioid-induced hyperalgesia: A qualitative systematic review. Anesthesiology. 2006 Mar; 104(3):570-87.

12. Lee C, Kim YD, Kim JN. Antihyperalgesic effects of dexmedetomidine on high-dose remifentanil-induced hyperalgesia. Korean J Anesthesiol. 2013 April; 64(4):301-7.

13. Zheng Y, Cui S, Liu Y, Zhang J, Zhang W, Zhang J, et al. Dexmedetomidine prevents remifentanil-induced postoperative hyperalgesia and decreases spinal tyrosine phosphorylation of $\mathrm{N}$-methyl-d-aspartate receptor 2B subunit. Brain Res Bull. 2012 Mar; 87(4-5):427-31.

14.Gurbet A, Basagan-mogol E, Turker G, Ugun F, Kaya FN, Ozcan B. Intraoperative infusion of dexmedetomidine reduces perioperative analgesic requirements. Can J Anaesth. 2006 Jul; 53(7)646-52.

15. Lee YY, Wong SM, Hung CT. Dexmedetomidine infusion as a supplement to isoflurane anaesthesia for vitreoretinal surgery. BrJ Anaesth. 2007 Apr; 98(4):477-83. 16. Fragen RJ, Fitzgerald PC. Effect of dexmedetomidine on the minimum alveolar concentration (MAC) of sevo- flurane in adults age 55 to 70 years. J Clin Anesth. 1999 Sep;11(6):466-70

17. Runciman WB, Kluger MT, Morris RW, Paix AD, Watterson LM, Webb RK. Crisis management during anaesthesia: the development of an anaesthetic crisis management manual. Qual Saf Health Care. 2005 Jun ;14(3):e1 18. Bryant $\mathrm{H}$, Bromhead $\mathrm{H}$. Intraoperative hypotension anaesthesia tutorial of the week 1482009 ;(August):1-6. http://www.wfsahq.org/components/com_virtual_library/media/aee44878629d22359 a 4dd 8dc54b1d91f-cfe3bb5b9f1b02898b-

51ca98199c21e8-148-Intraoperative-hypotension.pdf 19. Klinger RY, White WD, Hale B, Habib AS, Bennett-Guerrero E. Hemodynamic impact of dexmedetomidine administration in 15,656 noncardiac surgical cases. J Clin Anesth. 2012 May;24(3):212-20

20. Biccard BM, Goga S, de Beurs J. Dexmedetomidine and cardiac protection for non-cardiac surgery: a meta-analysis of randomised controlled trials. Anaesthesia. 2008 Jan; 63(1):4-14.

21. Sneyd JR, Camu F, Doenicke a, Mann C, Holgersen $\mathrm{O}$, Helmers $\mathrm{JH}$, et al. Remifentanil and fentanyl during anaesthesia for major abdominal and gynaecological surgery. An open, comparative study of safety and efficacy. Eur J Anaesthesiol. 2001 Sep;18(9):605-14

22. Shank ES, Sheridan RL, Ryan CM, Keaney TJ, Martyn JA. Hemodynamic responses to dexmedetomidine in critically injured intubated pediatric burned patients: a preliminary study. J Burn Care Res. 2013 May-Jun; 34(3):3117.

23. Salman N, Uzun S, Coskun F, Salman MA, Salman AE, Aypar U. Dexmedetomidine as a substitute for remifentanil in ambulatory gynecologic laparoscopic surgery. Saudi Med J. 2009 Jan; 30(1):77-81.

24. Jung HS, Joo JD, Jeon YS, Lee JA, Kim DW, In JH, et al. Comparison of an intraoperative infusion of dexmedetomidine or remifentanil on perioperative haemodynamics, hypnosis and sedation, and postoperative pain control. J Int Med Res. 2011;39(5):1890-9. PubMed.

25. Cheng YC,Vyas A, Hymen E,Perlmuter LC. Gender differences in orthostatic hypotension. Am J of Med Sci. 2011 Sep;342(3):221-5

26. Kheterpal S, O'Reilly M, Englesbe MJ, Rosenberg AL, et al. Preoperative and intraoperative predictors of cardiac adverse events after general, vascular, and urological surgery. Anesthesiology. 2009 Jan;110(1):58-66 